\title{
ASSESSING THE ROLE OF OPTICAL HEAD-MOUNTED DISPLAYS IN EDUCATION: AN INVESTIGATION OF GOOGLE GLASS IN CREATING LEARNING PORTFOLIOS AND PROVIDING FEEDBACK
}

\author{
G. Dafoulas, C. Maia, M. Loomes \\ Middlesex University (UNITED KINGDOM)
}

\begin{abstract}
Technology Enhanced Learning is a field that has seen impressive developments over the past few years. Educators have experimented with the use of web technologies, introduced innovative e-learning approaches, extended the role of virtual learning environments and introduced learning analytics. The authors' research aims to investigate how ubiquitous computing and augmented reality can further support students in a range of learning activities. In particular, this paper discusses a research study in the role of Optical Head-Mounted Displays (OHMD) in education. Emphasis is given on how the technology can enhance learning through the provision of additional support via augmented reality.
\end{abstract}

The paper describes how OHMD, and more specifically Google Glass has been used by students in a Higher Education Institution as part of their assessment.

The research aim is twofold as it considers:

(i) the role of OHMD in supporting students during the creation of learning portfolios which can be used for formative and summative assessment, and

(ii) the impact OHMD technology has in providing alternative ways of feedback.

The scope of the research is to assess the suitability of the technology, the benefits that can be introduced in educational contexts as well as the perceived value of the technology from the learners' point of view.

The first part of the study described in the paper describes how learners have used OHMD to construct a portfolio of learning evidence through cooperative evaluation of their work. In particular the study involved students using Google Glass to take snaps of their work, while recording a video diary of their contribution towards group coursework. Users reflected on the experience in terms of ease of use, simplicity and usefulness. They also evaluated the effectiveness of using OHMD during specific tasks including reading, writing and browsing.

The second part of the study is focused on providing feedback by using OHMD to attach vignettes on pictures of presentations. The technology is used for commenting on presentation content and delivery, while it is investigated as an alternative for providing feedback on practical activities. The paper also provides a detailed discussion of preliminary findings from the pilot with 92 participants studying at first and final years of a University degree.

Keywords: Optical Head-Mounted Displays, Google Glass, Augmented Reality, Wearable computers, Feedback. 